\title{
About feeding children: factor structure and internal reliability of a survey to assess mealtime strategies and beliefs of early childhood education teachers
}

Taren Swindle ${ }^{1 *}$ D, Madeleine Sigman-Grant ${ }^{2}$, Laurel J. Branen ${ }^{3}$, Janice Fletcher ${ }^{4}$ and Susan L. Johnson ${ }^{5}$

\begin{abstract}
Background: Children spend a substantial amount of time in early care and education (ECE) settings and may eat a majority of their diet in this setting. While there are several instruments focused on measuring factors of the ECE environment that may influence diet and weight outcomes, there are few comprehensive, valid, and reliable measures for collecting self-report of ECE providers' feeding practices. The purpose of this study was to establish the factor structure and internal reliability of a survey developed to measure practices and beliefs of ECE providers relative to feeding children.

Methods: Licensed ECE centers from CA, CO, ID and NV were included in this cross-sectional survey study. The sample was stratified by states and census regions to yield equal numbers of centers from each category. The total sample distribution included 1600 randomly selected centers and up to 8000 staff members (who represented teachers, aides, assistants, or cooks); 1178 surveys were completed. We conducted an exploratory, unrestricted factor analysis as well as parallel analyses to inform the number of factors to be extracted.

Results: Factors within Structural Mealtime Strategies included Adult Control of Foods Consumed (KuderRichardson $[K R]=0.67)$, Bribing with Sweet Foods $(K R=0.70)$, and Supportive Adult Roles at Mealtime (KR=0.55). Factors in Verbal Mealtime Strategies included Supporting Children's Eating Self-regulation $(K R=0.61)$, Pressure to Eat $(K R=0.58)$, and Social Comparisons $(K R=0.59)$. Beliefs about Mealtime factors were Autonomy Promoting $(a=0.64)$, Coercive Beliefs $(a=0.77)$, and Concern-Based Control ( $a=0.60)$.

Conclusions: The AFC Strategies and Beliefs Survey provides a promising self-report instrument with a strong factor structure consistent with the extant literature to measure practices and beliefs related to feeding and mealtimes in the ECE setting. Feeding young children in group settings differs in many ways from feeding in a family setting; hence it is important that measures such as the AFC Strategies and Beliefs Survey capture unique aspects of the ECE feeding environment.
\end{abstract}

Keywords: Early care and education, Childcare, Preschoolers, feeding, measurement

\footnotetext{
* Correspondence: tswindle@uams.edu

${ }^{1}$ Department of Family and Preventive Medicine, University of Arkansas for

Medical Sciences, 521 Jack Stephens Drive, Little Rock, AR 72205, USA

Full list of author information is available at the end of the article
}

(c) The Author(s). 2018 Open Access This article is distributed under the terms of the Creative Commons Attribution 4.0 International License (http://creativecommons.org/licenses/by/4.0/), which permits unrestricted use, distribution, and reproduction in any medium, provided you give appropriate credit to the original author(s) and the source, provide a link to the Creative Commons license, and indicate if changes were made. The Creative Commons Public Domain Dedication waiver (http://creativecommons.org/publicdomain/zero/1.0/) applies to the data made available in this article, unless otherwise stated. 


\section{Background}

According to the National Household Education Survey, $41 \%$ of children in the U.S. from birth through five years of age are in nonrelative care outside the home (including those attending center-based care) [1]. Given that children may spend long hours in Early Care and Education (ECE) settings, they may consume up to $2 / 3$ of their daily nutrient intake [2] while away from home. These experiences may influence lifelong eating, which in turn can impact health, including weight status [3]. To address nutritional needs, various "Best Practice" policies have been proposed as suitable standards for use throughout ECE [2, 4]. Best Practice is a term used across health care, business, government, industry, and in our case ECE, to denote "a procedure that has been shown by research and experience to produce optimal results and that is established or proposed as a standard suitable for widespread adoption" [5]. If followed, these guiding documents are proposed to support increased quality of care in the ECE setting. As noted by Larson et al. (2011), not only should ECE settings ensure adequate nutrition, they also should provide "a supportive environment for practicing skills and trying new foods" [6] (p. 1345). Thus, it becomes increasingly important to understand the mealtime environments and feeding strategies ECE providers use to instill healthy eating behaviors in young children using these guidance documents as a framework.

There is a robust literature on parental feeding practices, including both observational and self-reported data, which have identified a number of child feeding constructs. Less work has been done to operationalize child feeding constructs in ECE settings; however, it is likely that some parental feeding constructs have application. Parental feeding strategies that have been predictive of negative child outcomes (e.g., decreased intake of and preference for healthy foods, excess weight, overeating) include authoritarian feeding practices [7-9], restricted access to palatable foods [10-12], use of bribery and coercion $[13,14]$, permissive and neglectful attitudes towards feeding [15], and pressure to eat $[16,17]$. Additionally, perception of the child's weight $[16,17]$, cultural influences on child feeding [15, 18], and mealtime structure and routine [19] may modulate adult feeding practices making the study of feeding complex.

Much of the research focused on ECE feeding strategies has relied on constructs and surveys from the parent feeding literature. For example, several studies reporting the impact of ECE mealtime interventions utilized the Child Feeding Questionnaire [20-22] or the Child Feeding Styles Questionnaire [20, 23, 24], both of which were designed for use with parents. While acknowledging that there is terminology in the parental feeding literature that likely applies to ECE feeding, [25] there are also likely to be important differences. Thus, the application of these instruments to educators may not reflect the nuances of unique feeding transactions in this distinct setting or group of caregivers [26]. There are a few studies that have focused on educators specifically. One study by Gubbels and colleagues [27] examined the factor structure and internal consistency of the parent-focused Comprehensive Feeding Practice Questionnaire, as adapted for the ECE providers. Another instrument, the Environmental Policy Assessment and Observation (EPAO) Self Report, includes subscales assessing educator feeding practices and has examined test-retest reliability and validity $[28,29]$ including predictive value of EPAO-measured provider behaviors on children's dietary intake. [30] These items focus on whether the teacher sits with the children, what the teacher eats in the classroom, and the teacher's strategies to encourage healthy eating. Additional development of feeding assessments that are specific to the ECE setting represents an opportunity to capture the complexity of feeding children in group settings and the distinct challenges and teachable moments related to eating and mealtime in which ECE staff participate daily. Such a measure could capture ECE provider feeding practices that have the potential to influence child nutrition and weight outcomes.

Despite the scarcity of tools specific to ECE feeding practices, there are other valuable related assessments. Some existing instruments include items which assess personal nutrition knowledge, dietary intake and weight management behaviors of ECE providers [31-33]; others assess policies and characteristics of the ECE environment related to obesity prevention factors [28, 34, 35]. These instruments have successfully measured environmental factors including food quality, promotion of physical activity, water access, screen time, and nutrition education for the children. Lastly, some self-report measures have focused on menu quality [36] or physical activity [37]. As one specific example, The Wellness Children Care Assessment Tool includes questions about policy related to feeding (e.g., adults not pushing children to eat more). [38]. Thus, while previous instruments have measured some aspects of feeding children in group settings, the development of a tool specifically designed for the group feeding context of ECE, based upon input from ECE directors, staff and policy makers, represents a potential addition to existing methodology.

The About Feeding Children Study was conducted between 2002 and 2005. [39] The original questionnaire was developed, in part, to capture the strategies and beliefs of ECE providers during mealtimes. As noted above, since that time other instruments have been designed to investigate feeding practices in the ECE setting. While incorporating some features of the ECE setting, many 
constructs still pertain to parental feeding. Given that the AFC study was constructed almost entirely from the ECE perspective, the aim of this study was to explore the psychometrics of the AFC questionnaire (e.g., factor structure, internal reliability), shorten its length, and determine its potential utility for use in research and practice to measure feeding children in group settings.

\section{Methods}

\section{Study design}

The AFC group was a consortium of nutrition and child development professionals from academic institutions in three western states. The consortium focused on enhancing children's feeding and mealtime experiences in the child care setting. The purpose of the AFC Survey was to expand our knowledge of mealtimes in ECE centers across four Western states-California (CA), Colorado (CO), Idaho (ID), and Nevada (NV). As part of a larger study, a survey targeted to ECE providers from licensed centers serving children 18-60 months of age was designed and conducted. We aimed to capture diversity with respect to geographic areas, center size, ethnicity and level of experience of ECE providers. Our specific aims included gathering data regarding factors influencing ECE providers' child feeding practices and framing these data in the context of providers' experience, training, and personal health characteristics. The Institutional Review Boards from each university approved all aspects of this research. Informed consent was obtained from all participants. This included implied consent from those returning surveys and signed consent from those in face-to-face interviews.

\section{Setting and participants}

A stratified random sample of licensed ECE centers from CA, CO, ID and NV was selected, and English-speaking staff from these centers who worked with children 1860 months of age were invited to participate in the survey. Licensing and accreditation agencies within each state supplied databases of ECE centers, and Head Start and the Child and Adult Care Food (CACFP) Programs from $\mathrm{CO}$, ID and $\mathrm{NV}$ also provided information. The final database contained 11,661 centers. Among center-based ECE there are several different types: (1) programs that are federally funded and regulated, and have specific education requirements for staff (e.g., Head Start), (2) programs that are state funded and regulated, and (3) programs that adhere to minimum licensing standards only (e.g., private). The sample was stratified by states and census regions to yield equal numbers of centers from each state and census region. The number sampled per state $(n=400)$ was chosen based on the fewest number of licensed centers within a state (NV with $n=418)$. The total sample distribution included
1600 randomly selected centers and up to 8000 staff members ( 5 per center who could be teachers, aides, assistants, or cooks). [39]

\section{Development of questionnaire Initial stage}

Figure 1 depicts the development process, including steps to identify content for the AFC survey. In 2001, the research team reviewed the extant literature along with professional guidelines from CACFP, Head Start, American Academy of Pediatrics, National Association for the Education of Young Children, and American Dietetic Association [39]. A list of 13 guidelines was compiled. During the review, it was noted that few instruments regarding the ECE environment from the perspective of the physical, emotional, and social developmental needs of the center, the staff, and the child existed at that time. In 2001-2002, in-depth interviews were conducted in English by trained professionals following a detailed script. Providers were asked to describe ECE ideal feeding experiences; current child-feeding beliefs and practices; interpretation of feeding guidelines; concerns about child feeding; and knowledge of child development and nutrition information. This phase concluded with a stakeholder meeting in 2002 during which national experts participated in operationalizing feeding guidelines and constructs. The expert panel consisted of one parent; two center directors; two feeding sponsors; three CACFP administrators (representing CO, ID, and NV); one specialist for children with special needs; and one licensing authority. Using a modified Delphi method, each member was asked to individually rank their top seven guidelines from a list of 19 generated from existing literature and the aforementioned 13 guidelines. Next, the expert panel was organized into three groups to reprioritize the guidance. Three major themes were generated: allowing children to self-serve, having adults eat the same foods as the children, and not using food as a reward and punishment. The combined information from each study component was used to identify further potential survey themes. Then the entire group reconvened to discuss items to be included in the questionnaire. Following this activity, panel members met in small groups to discuss what behaviors would need to be observed to operationalize each guideline into "Best Practice." Interviews and meetings were audiotaped and transcribed, and field notes were added.

\section{Content of survey}

Based upon these data for potential survey themes, we identified constructs related to feeding and crafted items that tapped these constructs. The following topic areas included in the survey: 1) current child feeding practices, 2) the degree of external control exerted in child feeding practices, 3) administrative routines used in child 


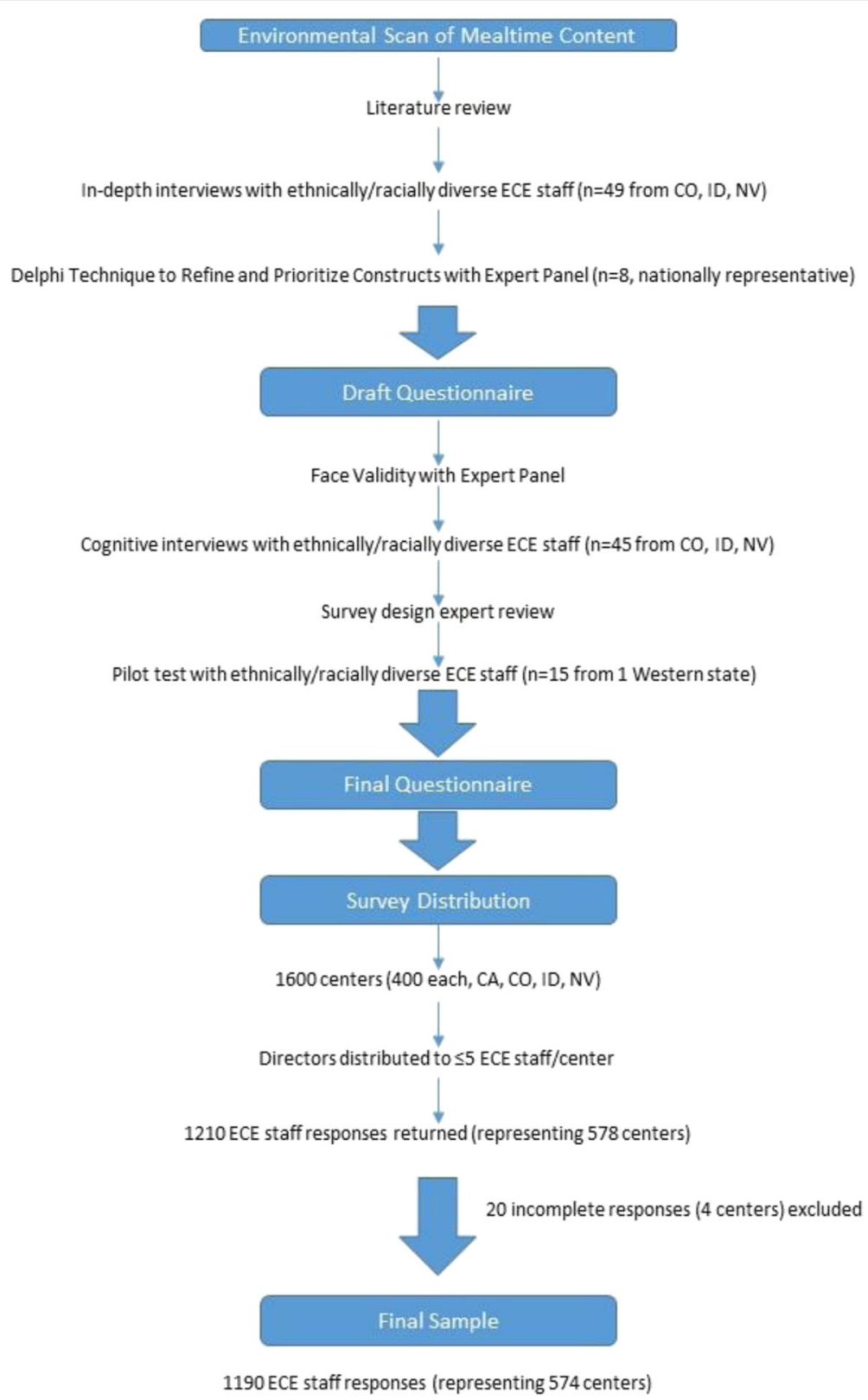

Fig. 1 About feeding children strategies and beliefs survey questionnaire development, study design and survey distribution

feeding, and 4) perceived barriers to creating optimal mealtimes for children. Participants were directed to consider their usual mealtime experiences only, as it was determined from the interviews that providers view snack times as serving a different purpose than mealtimes. ECE staff also provided demographic information including ethnicity, education level and years of experience. Items were predominately forced choice, and response sets were 5-7-point Likert scales or Yes/No responses. The different response formats were developed based upon item-specific feedback from pilot subjects. Endorsement of items was defined and coded to indicate that an item reflected the characteristics of the respondent (i.e., $0=$ never or infrequently; $1=$ some to all of the time), consistent with survey research terminology. [39] Although scales differed by item set, this definition was applied consistently to all feeding practices. This standardized the scale of these items to reduce loadings explained by method variance. Practices that require improvement or change relative to Best Practice guidance were identified as 'Unsupportive Practice.'

In 2004, drafts of the questionnaire were tested using cognitive interviewing [39] with ECE staff from ethnic groups including Hispanic, African American, and 
Non-Hispanic White. Items and responses were evaluated and adjusted for readability, comprehension, perceptions, completeness of response sets, and clarity of instructions. Items then were revised and reviewed for content and format by a survey design expert. After further refinement, the survey was pilot-tested with 15 individuals in the Denver area who varied in ethnic origin. Researchers noted time to complete the entire survey (mean $=20.2 \pm 7.2 \mathrm{~min}$ ), any missed items, and items for which no response was recorded. Minor changes were made, and the final survey included 60 questions, some of which requested multiple responses, for a total of 171 items. [39]

\section{Format}

Surveys were formatted using TELEform Elite v8. [39] This automated system allows for scanning of paper-based surveys to extract data directly into datafiles.

\section{Distribution of surveys}

The tailored design method for unsolicited mailed questionnaires was closely followed. [39] Using this approach, beginning in June 2004, approximately one week prior to mailing, pre-notification letters announcing the survey were sent to state licensing agencies and directors of the 1600 centers. Center director letters included a flyer to post, with the aim of alerting staff about the study.

Packets containing five staff questionnaires, along with an explanatory cover letter and small educational incentives, were sent to ECE directors. Directors were instructed to make materials available to facilitate staff's ability to anonymously complete the survey. The ECE director determined where and how surveys were distributed but were instructed to maintain staff anonymity. A pre-stamped return envelope was included with each staff survey so that the survey could be anonymously completed, sealed and mailed immediately. One week after the first mailing, a thank you/reminder flyer was sent to directors for posting. Another reminder was distributed two months later. Receipt of returned surveys was logged daily into a database using tracking code labels. Surveys were visually checked for torn and missing pages. Surveys were scanned, verified for errors, and flagged data fields were either corrected or coded as missing. A $41 \%$ center response rate was achieved.

\section{Data analyses}

Participant characteristics including means, SDs, and frequencies were computed. Descriptive statistics and distributions were calculated for each item response of each caregiver survey returned $(N=1178$, representing 568 centers). Given the broader scope of the AFC survey, 55 of the 171 items were extracted for these analyses. These specific items were selected a priori for inclusion in initial descriptive analyses because they asked about provider child feeding beliefs, attitudes and practices. Excluded item content that was not specific for these analyses included questions about experiences with food insecurity in the classroom, [39] barriers to feeding children (e.g., rules, equipment), and teaching at meals (e.g., manners, social skills). To distinguish this shortened instrument from the original tool, these items will henceforth be referred to as the AFC Strategies and Beliefs Survey.

AFC Strategies and Beliefs Survey items were grouped into three conceptual categories prior to conducting factor analyses: Structural Mealtime Strategies, Verbal Mealtime Strategies, and Beliefs about Mealtime. These categories are consistent with the recent application of the Belsky model [40] to ECE settings, which illustrates how educators' attitudes and beliefs can predict behaviors (i.e., practices and interactions with children). We further categorized types of behaviors into verbal and non-verbal (i.e., structural). This separation reflects early social modeling literature that documents the differential influence of adults' words and actions on child behavior. [41-43] Our conceptual grouping would allow for examination of inconsistency between beliefs and practices as well as between actions and words, which may have distinct impacts on children as well. [43] All items were coded such that higher scores were more consistent with supportive practice. Structural and Verbal Mealtime Strategy items with $75 \%$ of respondents or greater indicating the same answer were excluded from analyses due to limited variance (i.e., inability to discriminate on the underlying construct) [44]. This is consistent with previous studies measuring mealtime factors, which eliminated items with ceiling or floor effects $[45,46]$. There were no ceiling or floor effects observed for the Belief items; therefore, all were retained.

To explore the factor structure of items collected through the AFC Strategies and Beliefs Survey, we conducted an exploratory, unrestricted factor analysis within each construct. Direct oblimin rotation allowed for correlation between items. Analyses were conducted in MPLUS Version 7 [47] using the appropriate correlation matrix for the nature of the variables. That is, Structural and Verbal Strategies were measured or summarized on a binary scale $(0,1)$, and a polychoric correlation matrix was used to appropriately estimate the model with variables of this type. For these models, a weighted least squares estimation (WLSMV) was used to account for the categorical nature of variables [48, 49]. Items in the Beliefs about Mealtime construct were measured on a 1-5 scale. Thus, maximum likelihood estimation was employed for this construct. A parallel analysis [50] was conducted within each conceptual category to determine eigenvalues of factors that would be expected among 
randomly generated data with no factor structure. In our EFA analyses, only factors with eigenvalues greater than those generated in the parallel analyses were retained. When consistent with previous work done with parents, factors were named to reflect the Content Map of Food Parenting Practices by Vaughn and colleagues. [25] For all constructs, a factor loading greater than .40 was deemed acceptable [48, 49].

Missing data rates ranged from 8.4 to $16.3 \%$ per variable in the EFA analysis. Characteristics associated with missing data were identified and included to improve Full Information Maximum Likelihood (FIML) estimation. FIML includes all cases by giving less weight to incomplete response sets and more weight to complete response sets in the final likelihood function [51]. Correlations between factors within constructs were obtained using the FIML estimator. Internal consistency within a factor was estimated using Cronbach's alpha for scales with continuous items and Kuder-Richardson values for scales composed of binary items. A threshold of .50 was adopted for internal consistency given the limited number of items in suggested sub-scales and the exploratory nature of this study $[52,53]$.

\section{Results}

Participants with complete data were no different than those with incomplete data in terms of ethnicity, job description (i.e., assistant versus lead educator), gender, employed by Head Start (yes/no), socioeconomic status of families served, geographic area, state surveyed, level, or self-reported BMI. However, participants with missing data were significantly less likely to be from a center with funding from CACFP $(p=0.03)$ and were significantly older $(p<0.001)$ with significantly more years of experience in the field $(p=0.001)$. Thus, these variables were included in model datasets as mechanisms to account for missing data.

\section{Item descriptive statistics}

Table 1 presents sample demographics. Table 2 presents the percent of participants that endorsed (indicating support, approval and/or usage) each item for both Structural and Verbal Mealtime Strategies. Endorsement percentages indicated that eight Mealtime Structure items reflected floor $(n=3)$ and ceiling effects $(n=5)$; these items were not included in further analyses. In total, nine items were excluded from further analyses for Verbal Mealtime Strategies due to limited variability; mostly $(n=7)$ due to ceiling effects. The two items receiving the lowest endorsement both began with "I never." All Belief items were retained as no ceiling effects were observed. Thus, in summary, 14 items were included for EFA analyses within structural mealtime strategies; 13 items were included for verbal mealtime
Table 1 Demographic and personal descriptive statistics for the survey respondents

\begin{tabular}{|c|c|c|}
\hline Provider characteristics & $(N=1178)$ & \\
\hline & Frequency & \\
\hline Sex & $n$ & $\%$ \\
\hline Female & 1157 & 98.2 \\
\hline Male & 21 & 1.7 \\
\hline Race \& Ethnicity & $n$ & $\%$ \\
\hline White & 871 & 73.9 \\
\hline Black & 68 & 5.8 \\
\hline Hispanic (may be White, Black or Other) & 179 & 15.2 \\
\hline Other & 225 & 19.1 \\
\hline Education & $\mathrm{n}$ & $\%$ \\
\hline High school or less & 261 & 22.2 \\
\hline Some College & 435 & 36.9 \\
\hline Associates Degree & 195 & 16.5 \\
\hline BA/BS Degree & 210 & 17.8 \\
\hline Graduate Degree & 56 & 4.8 \\
\hline Missing & 21 & 1.8 \\
\hline Role at Agency & $N$ & $\%$ \\
\hline Lead Teacher & 948 & 80.5 \\
\hline Assistant Teacher & 164 & 13.9 \\
\hline Missing & 66 & 5.6 \\
\hline Center Type (multiple answers may apply) & $\mathrm{N}$ & $\%$ \\
\hline Head Start & 97 & 8.2 \\
\hline CACFP & 322 & 27.3 \\
\hline & Mean & SD \\
\hline Age & 36.8 & 12.7 \\
\hline Body Mass Index (BMl; kg/m²) & 26.6 & 6.3 \\
\hline Experience in child care in years & 9.5 & 7.7 \\
\hline
\end{tabular}

strategies; and 11 items were included in the EFA for beliefs about mealtime.

\section{Exploratory factor analysis by construct Structural mealtime strategies}

Parallel analysis suggested extraction of factors with eigenvalues greater than 1.2. Three factors met this criterion. These factors were defined as Adult Control of Foods Consumed (e.g., "The children have to take at least one bite."); Bribing with Sweet Foods (e.g., "I have the children try the food before they can have sweet foods."); and Supportive Adult Roles at Mealtime (e.g., "I eat the same food as children at mealtime."). Two items did not load onto any factor (see Table 3). Kuder-Richardson values (indicating internal consistencies) were 0.67, 0.70, and 0.55 for the three factors, respectively. The correlation between Adult Control of Foods Consumed and Bribing with Sweet Foods was significant and positive 
Table 2 Item pool and endorsement for structural and verbal mealtime strategies

\begin{tabular}{|c|c|c|}
\hline & $\%$ Endorsement & $\%$ Endorsement \\
\hline \multicolumn{2}{|l|}{ Structural Mealtime Structures } & \multirow{2}{*}{$\begin{array}{l}\text { If children do not want to stop eating, I explain } \\
\text { that they need to leave enough for everyone }\end{array}$} \\
\hline \multirow{2}{*}{$\begin{array}{l}\text { When children are very thin, I serve them } \\
\text { more of everything. }\end{array}$} & \multirow{2}{*}{10.5} & \\
\hline & & \multirow{2}{*}{$\begin{array}{l}\text { If picky children don't want to eat, I tell them } \\
\text { to take at least one bite of everything. }\end{array}$} \\
\hline To help children eat, I start feeding them. ${ }^{a}$ & 17.1 & \\
\hline $\begin{array}{l}\text { If picky children don't want to eat, I start } \\
\text { feeding them so they get interested. }{ }^{\text {a }}\end{array}$ & 21.2 & $\begin{array}{l}\text { When children are very thin, I praise them for } \\
\text { eating to get them to eat more. }\end{array}$ \\
\hline $\begin{array}{l}\text { I don't let them have seconds of other foods } \\
\text { until they try the new food. }\end{array}$ & 25.5 & $\begin{array}{l}\text { To help children eat, I suggest that they need } \\
\text { to eat more. }\end{array}$ \\
\hline Both children and staff pass the food. & 31.3 & $\begin{array}{l}\text { If picky children don't want to eat, I ask if their } \\
\text { tummy is full. }\end{array}$ \\
\hline $\begin{array}{l}\text { To help children eat, I serve sweet food after } \\
\text { they eat the rest of the food on their plates. }\end{array}$ & 35.7 & $\begin{array}{l}\text { If picky children don't want to eat, I suggest } \\
\text { that they start eating what is on their plate. }\end{array}$ \\
\hline $\begin{array}{l}\text { If picky children don't want to eat, I wait to } \\
\text { serve them sweet foods if they do not eat } \\
\text { something from their plate. }\end{array}$ & 40.2 & $\begin{array}{l}\text { If children do not want to stop eating, I tell } \\
\text { them they can't have more of some foods. }\end{array}$ \\
\hline The children have to take at least one bite. & 42.5 & I ask children if their stomach are full. \\
\hline I have the children try the food before they & 43.9 & I talk about food at mealtime. \\
\hline can have sweet foods. & & \multirow{2}{*}{$\begin{array}{l}\text { I notice and comment to the child who is eating } \\
\text { well. }^{\mathrm{a}}\end{array}$} \\
\hline I sit with the children at mealtime. & 48.1 & \\
\hline When children are served new food, I try the & 53.3 & \multirow{3}{*}{$\begin{array}{l}\text { I teach the children about new foods. }{ }^{\text {a }} \\
\text { If children do not want to stop eating, I tell } \\
\text { them they can't have any more to eat. }{ }^{\text {. }}\end{array}$} \\
\hline new food all of the time. & & \\
\hline I eat the same food as children at mealtime. & 53.6 & \\
\hline I have the children eat one bite of each food. & 53.8 & $\begin{array}{l}\text { If picky children don't want to eat, I ask them } \\
\text { to eat something on their plate. }\end{array}$ \\
\hline $\begin{array}{l}\text { I have the children finish their meal before } \\
\text { eating sweet foods. }\end{array}$ & 54.8 & I ask the children to take a bite. ${ }^{a}$ \\
\hline $\begin{array}{l}\text { When children are very thin, I offer them } \\
\text { more of the foods they like. }\end{array}$ & 56.4 & $\begin{array}{l}\text { To help children eat, I explain to the children } \\
\text { that the food will make them grow and be healthy. }\end{array}$ \\
\hline $\begin{array}{l}\text { If children do not want to stop eating, } \\
\text { I try to distract them with another activity. }\end{array}$ & 61.7 & $\begin{array}{l}\text { Items dropped from further analyses because of limited variability defined as } \\
>75 \% \text { selecting one response option. Italics are used to indicate items } \\
\text { conceived as best practice }\end{array}$ \\
\hline $\begin{array}{l}\text { Children are involved in serving themselves at } \\
\text { mealtime. }\end{array}$ & 65.1 & \\
\hline $\begin{array}{l}\text { I have the children eat nutritious food } \\
\text { before "junk" food. }\end{array}$ & 82.3 & $\begin{array}{l}(r=0.55, p<0.05) \text {. Supportive Adult Roles at Meal- } \\
\text { time were not significantly correlated with Bribing }\end{array}$ \\
\hline I let children decide how much to eat. ${ }^{a}$ & 83.3 & with Sweet Foods $(r=0.37, p>0.05)$ or Coercive \\
\hline I try the new food with the children. ${ }^{\text {a }}$ & 86.4 & Control $(r=0.04, p>0.05)$ \\
\hline I offer new foods at mealtime or snack time..$^{a}$ & 87.7 & \\
\hline $\begin{array}{l}\text { If children do not want to stop eating, } \\
\text { I send them away from the table. }\end{array}$ & 91.9 & $\begin{array}{l}\text { Verbal mealtime strategies } \\
\text { Three factors with eigenvalues greater than } 1.15 \text { were }\end{array}$ \\
\hline Verbal Mealtime Strategies & & extracted based on the parallel analysis. Factors 1,2 , and \\
\hline I never ask children if they want more to eat. ${ }^{a}$ & 5.4 & $\begin{array}{l}3 \text { were named Supporting Children's Eating } \\
\text { Self-regulation (eg "I ask the children if their stomachs }\end{array}$ \\
\hline $\begin{array}{l}\text { I never encourage children to eat the amount } \\
\text { I think they need. }{ }^{\text {. }}\end{array}$ & 14.0 & are full."); Pressure to Eat (e.g., "I tell the children if they \\
\hline $\begin{array}{l}\text { To help children eat, I point out other children } \\
\text { who are eating more. }\end{array}$ & 31.4 & "I point out other children who are eating more." \\
\hline $\begin{array}{l}\text { If children do not want to stop eating, I ask } \\
\text { if their tummy is full. }\end{array}$ & 33.8 & spectively. Three items did not load onto any factor and \\
\hline I tell the children if they have not eaten enough. & 39.8 & $\begin{array}{l}\text { were eliminated (Table 4). The Supporting Children's } \\
\text { Eating Self-regulation and Social Comparisons factors }\end{array}$ \\
\hline $\begin{array}{l}\text { If picky children don't want to eat, I let them } \\
\text { know they don't have to eat. }\end{array}$ & 49.3 & were negatively correlated $(r=-0.31, p<0.05)$. Pressure \\
\hline $\begin{array}{l}\text { I say something like "Pat is eating green beans. } \\
\text { Why don't you eat some?" }\end{array}$ & 50.2 & $\begin{array}{l}\text { Eating Self-regulation }(r=-0.18, \quad p>0.05) \text { or Social } \\
\text { Comparisons }(r=0.39, p>0.05) \text {. }\end{array}$ \\
\hline
\end{tabular}

Table 2 Item pool and endorsement for structural and verbal mealtime strategies (Continued)

mealtime strategies (Continued)
. . 
Table 3 Factor loadings and frequency of endorsement for structural mealtime strategies

\begin{tabular}{|c|c|c|c|}
\hline Item content & $\begin{array}{l}\text { Adult control of } \\
\text { foods consumed }\end{array}$ & $\begin{array}{l}\text { Bribing with } \\
\text { sweet foods }\end{array}$ & $\begin{array}{l}\text { Supportive adult } \\
\text { roles at mealtime }\end{array}$ \\
\hline I don't let them have seconds of other foods until they try the new food. & 0.74 & & \\
\hline The children have to take at least one bite. & 0.88 & & \\
\hline I have the children eat one bite of each food. & 0.76 & & \\
\hline I have the children try the food before they can have sweet foods. & & 0.50 & \\
\hline I have the children finish their meal before eating sweet foods. & & 0.63 & \\
\hline I wait to serve them sweet foods if they do not eat something from their plate. & & 0.65 & \\
\hline I serve sweet food after they eat the rest of the food on their plates. & & 0.98 & \\
\hline I eat the same food as children at mealtime. & & & 0.76 \\
\hline I sit with the children at mealtime. & & & 0.48 \\
\hline Both children and staff pass the food. & & & 0.76 \\
\hline I try new foods with children (all or most of the time). & & & 0.48 \\
\hline I offer them more of the foods they like. & -0.02 & 0.38 & -0.22 \\
\hline I try to distract them with another activity. & 0.06 & 0.28 & -0.11 \\
\hline
\end{tabular}

\section{Beliefs about mealtime}

Similar to those for the other constructs, a parallel analysis suggested extraction of three factors for Beliefs about Mealtime (eigenvalues $>1.15$ ). The first factor was designated as Autonomy Promoting Beliefs (Cronbach's alpha $=0.64$; e.g., "Trying the new food with them will work to get children to try new foods."). The second factor was designated as Coercive Beliefs (Cronbach's alpha $=0.77$; e.g., "Having a "one bite" rule will work to get children to try new foods."). The third factor was designated as Concern-Based Control Beliefs (Cronbach's alpha $=0.60$; "When a child is feeling sad, it's okay to offer a cracker to help the child feel better.") (see Table 5). Autonomy Promoting Beliefs was not correlated with Coercive Beliefs $(r=-0.03, p>0.05)$ or with Concern-Based Control $(r=0.01, p>0.05)$. Coercive Beliefs and Concern-Based were positively, significantly correlated $(r=0.30, p<0.05)$. Figure 2 presents all components and constructs.

\section{Discussion}

The AFC Strategies and Beliefs Survey was designed to assess feeding beliefs and practices of ECE providers during mealtimes in ECE centers. The factor analyses and endorsement patterns suggest that the AFC Strategies and Beliefs Survey captured both Best Practice Guidance and Unsupportive Practice. Comparison of the AFC survey items with the American Academy of Nutrition and Dietetics benchmarks for nutrition in child care $[20,54]$ reveals that of the 12 guidance categories outlined by this position paper, 5 are addressed by the AFC survey (providers sit with children, providers eat meals with children, meals are served "family style," providers help children recognize internal cues, providers do not

Table 4 Factor loadings verbal mealtime strategies

\begin{tabular}{|c|c|c|c|}
\hline Item content & $\begin{array}{l}\text { Autonomy } \\
\text { supporting cues }\end{array}$ & $\begin{array}{l}\text { Autonomy } \\
\text { undermining cues }\end{array}$ & $\begin{array}{l}\text { Social } \\
\text { comparisons }\end{array}$ \\
\hline I ask the children if their stomachs are full. & 0.76 & & \\
\hline If children do not want to stop eating, I ask if their tummy is full. & 0.53 & & \\
\hline If picky children don't want to eat, I ask if their tummy is full. & 0.88 & & \\
\hline I tell the children if they have not eaten enough. & & 0.78 & \\
\hline If picky children don't want to eat, I suggest that they start eating what is on their plate. & & 0.46 & \\
\hline If picky children don't want to eat, I let them know they don't have to eat. & & 0.51 & \\
\hline To help children eat, I suggest that they need to eat more. & & 0.63 & \\
\hline I say something like "Pat is eating green beans. Why don't you eat some?" & & & 0.80 \\
\hline I point out other children who are eating more & & & 0.86 \\
\hline If children do not want to stop eating, I tell them they can't have more of some foods. & -0.04 & 0.25 & 0.24 \\
\hline If picky children don't want to eat, I tell them to take at least one bite of everything. & -0.03 & 0.34 & 0.28 \\
\hline When children are very thin, I praise them for eating to get them to eat more. & -0.01 & 0.36 & 0.36 \\
\hline
\end{tabular}


Table 5 Factor loadings beliefs about mealtime

\begin{tabular}{|c|c|c|c|c|}
\hline Item content & $\begin{array}{l}\text { Autonomy promoting } \\
\text { beliefs }\end{array}$ & $\begin{array}{l}\text { Coercive } \\
\text { beliefs }\end{array}$ & $\begin{array}{l}\text { Concern-based } \\
\text { control }\end{array}$ & Mean (sd) \\
\hline $\begin{array}{l}\text { Teaching children about new foods before offering the foods at mealtime } \\
\text { will work to get children to try new foods. }\end{array}$ & 0.66 & & & $2.61(0.67)$ \\
\hline Trying the new food with them will work to get children to try new foods. & 0.81 & & & $2.37(0.70)$ \\
\hline Children are more likely to try a new food after they see me eat it. & 0.43 & & & $1.99(0.84)$ \\
\hline $\begin{array}{l}\text { Having the new food on the table at mealtime and letting children decide when } \\
\text { to try it will work to get children to try new foods. }\end{array}$ & 0.42 & & & $2.72(0.90)$ \\
\hline Having a "one bite" rule will work to get children to try new foods. & & 0.63 & & $2.72(0.93)$ \\
\hline $\begin{array}{l}\text { Keeping them from having sweet foods until they try the new food will work } \\
\text { to get children to try new foods. }\end{array}$ & & 0.72 & & $2.88(0.99)$ \\
\hline Not having seconds of other foods unless they try the new food & & 0.83 & & $3.08(1.01)$ \\
\hline Suggesting they try a bite & & -0.43 & & $2.56(0.74)$ \\
\hline Adults know better than children how much children need to eat. & & & .81 & $3.48(1.25)$ \\
\hline If children put food on their plates, they should eat it. & & & .45 & $3.37(1.27)$ \\
\hline When a child is feeling sad, it's okay to offer a cracker to help the child feel better. & & & .41 & $3.76(1.20)$ \\
\hline
\end{tabular}

All belief items were measursed on 1-5 scale with lower scores corresponding to greater agreement. No items were reverse-coded before mean estimation

use controlling feeding practices). Two additional benchmarks (providers model healthful eating and providers teach children about nutrition) were included as items in the original survey but, due to $>75 \%$ endorsement of these strategies (and therefore limited variance or discrimination added by these items), were dropped for factor analyses. Benchmarks that were not addressed included information about training and education for providers, children and parents; these were gathered by our larger survey but not included in this analysis of feeding practices and beliefs. A further strength of the AFC Strategies and Beliefs Survey is that it includes

\section{Structural Mealtime Strategies}

- $\quad$ Adult Control of Foods Consumed (3 items)

- Bribing with sweet foods (4 items)

- Supportive Adult Roles at Mealtime (4 items) *

\section{Verbal Mealtime Strategies}

- Autonomy supporting strategies (3 items)

- Autonomy undermining strategies (4 items)

- Social comparisons (2 items) *

\section{Beliefs About Mealtimes}

- Autonomy promoting beliefs (4 items)

- Coercive beliefs (4 items)

- Concern-based control beliefs (3 items) *

Fig. 2 Components and constructs of the about feeding children mealtime strategies and beliefs survey items related to beliefs underlying the benchmarks that were assessed (e.g., beliefs about teaching children, attitudes about what works at meals, beliefs about children's self-regulation).

Results from exploratory factor analysis, parallel analysis, internal consistency estimates, and factor inter-correlations converge to suggest that the factors presented are definite, distinct, and internally reliable. This instrument is complementary to, yet distinct from, existing measures focusing on elements of ECE policies and environmental characteristics [55-57]. The inclusion of both beliefs and practices in the AFC survey provides a potential opportunity to document ECE self-reported strategies at mealtime but also to determine whether beliefs about child-feeding align with reported behaviors. Previously, only one instrument has included items about beliefs, knowledge and practices but not necessarily with an alignment among these items that could facilitate comparisons [58]. Additionally, based upon stakeholder input, items were developed which specifically asked about difficult to manage transactions-how to manage the presence of highly palatable, sweet foods that children seek to consume. These items provided insights into linkage of beliefs and practices. While not all ECE staff endorsed the belief that withholding sweet foods helps to get children to try new foods (Mean, $\mathrm{SD}=2.88,0.99$ ), $>40 \%$ of participants responded that they used this strategy to encourage children to try new foods. Additionally, the inclusion of items which capture verbal as well as structural practices is a strength and is unique to the AFC survey; verbal influences, such as praise and social comparisons, may be important in influencing child behaviors-negatively or positively and perhaps differentially over time. 
It should be acknowledged that the AFC survey focuses on feeding beliefs and strategies and does not address some important constructs measured by other instruments. For example, other instruments capture environmental influences on mealtime quality (e.g., noise level), $[28,55]$ the food environment [28], the use of nutrition education techniques [28], child involvement in food preparation, [27] screen use during mealtimes, [24, $28,55]$ and policies related to mealtimes in childcare [28]. That said, one advantage of the AFC survey is that its narrower focus allows for multiple items to address a single construct, which should produce a more robust assessment of practices and beliefs [44].

The development of the AFC Strategies and Beliefs survey was undertaken in a manner to reflect practices unique to a communal feeding setting with elements that may impact those practices. While there are feeding practices utilized by ECE staff that are consistent with parenting practices in the home setting, there also are unique practices that are necessitated by feeding children in group settings. Examples of such practices that were included in the AFC survey include social comparisons regarding children's eating behaviors (which can be easily made, given the number of children participating in mealtimes) and an emphasis on staff eating with children and engaging with children to pass food around the table. While a number of constructs related to parental feeding practices were not included in this survey (e.g., monitoring children's intake, perceived responsibility in child feeding [9]), these constructs do appear to some extent in other instruments that have been recently developed for the ECE setting [24, 27, 28, 55].

The resulting survey instrument provides a tool that measures nine distinct factors within three ECE child-feeding constructs (Fig. 2). Of the nine factors, six are consistent with the Vaughn et al. Content Map of Food Parenting Practices. [25] Unique factors were Social Comparisons, Concern-Based Control Beliefs, and Supportive Adult Roles at Mealtime which capture practices across two Vaughn Structures (Meal and Snack Routines and Modeling) and is consistent with other terminology in the literature. [59] Social Comparisons, while possible in a home environment, may be a strategy that is more likely to be used in the ECE feeding environment. Regardless, this is a potential difference with the conceptual model that has been constructed for parental feeding practices. Finally, Concern-Based Control Beliefs reflected things adults believe they should do for the child's best interest. Educators may have concerns about children's food insecurity, [40] feel accountable for ensuring children eat enough, and generally want children to feel positive in their classroom. This feeling of responsibility may result in a variety of thoughts and actions. Further work to determine the overlap and differences of feeding practices for parents and ECE is needed and could result in parallel maps that align with both home and child care environments.

Concerning the findings more broadly, as expected, ECE educators simultaneously agreed with practices and held beliefs that were both supportive and unsupportive of children's healthy eating development. To add further to the complexity of the ECE environment, educators indicated use of Best Practice Guidance without believing in their effectiveness for feeding young children. To fully represent and understand the impact of educators' feeding practices, we suggest all aspects should be included in measures of the ECE feeding environment.

\section{Structural mealtime strategies}

Adult Control of Foods Consumed, Bribing with Sweet Foods, and Supportive Adult Roles at Mealtime each were distinct and strong factors within Structural Mealtime Strategies. The Adult Control of Foods Consumed factor reflected items focused on ensuring children try all foods served (including new foods). While some have advocated for these strategies (e.g., Two Bite Club [60]), these practices may ignore child hunger/satiety and fail to value child choice [61]. The long-term impact of one or two bite "rules," rewards associated with trying foods, and the level of forcefulness with which these are employed, have been reported to have varying relationships with children's outcomes in a trial involving parents and in an experimental study without parents $[62,63]$.

The Bribing with Sweet Foods factor included items reflective of teacher strategies to withhold sweet foods as an incentive until children ate other foods served [14, 63]. Using ECE educators' input during development of these items, "sweet foods" was a term adopted broadly to include dessert foods and fruit. Through formative research to develop the items, we gleaned that this term reflected educators' position that fruit was a highly desirable food for children and could be considered to elicit as many problematic behaviors at mealtime as dessert. Existing literature (experimental, observational with parents, and intervention testing in schools) suggests that controlling access to food in this way is counterproductive and does not support intake of, or preference for "healthy" foods [13, 14, 64-66].

Supportive Adult Roles at Mealtime reflected items conceived as Best Practice Guidance (i.e., ECE staff sits, eats, and tries new food with children; children and staff pass foods). These practices are consistent with family-style meal service, a standard in Head Start settings [67] and an evidence-based guideline issued by the Academy of Nutrition and Dietetics. [68] Educators sitting with children and eating the same food has been associated with increased vegetable intake for children $[69,70]$ but has also been reported to be difficult to achieve, particularly when 
staffing is inadequate or when environmental demands are too high [71]. Conceptually, such strategies reflect previously observed parental modeling constructs $[72,73]$ that might be applicable to the ECE setting.

\section{Verbal mealtime strategies}

Supporting Children's Eating Self-regulation, Pressure to Eat, and Social Comparisons emerged as Verbal Strategies. Items in Supporting Children's Eating Self-regulation focused on directing children to their own sense of fullness and hunger to guide their eating. Use of Supporting Children's Eating Self-regulation may promote long-term self-regulation of eating and support children's attending to their internal signals of hunger and satiety, whereas adult directives can override or ignore the internal state of the child [54, 74-77]. The Pressure to Eat factor was comprised of items measuring educators' use of comments to guide children's eating based on their own perceptions (as opposed to the child's hunger/satiety) of how much the child needs to eat. Use of external adult control in the parental feeding domain has been associated with problematic outcomes for children's eating and weight status $[9$, 17, 78]. The third factor in Verbal Strategies, Social Comparisons, was comprised of two items that were less often endorsed, relative to other items. The content of these items reflected strategies to compare the amount or types of foods (e.g., green beans) eaten between a target child and another child in the classroom. Research on the impact of social comparisons on classroom learning has been found to lead to decreases in child motivation and empowerment [79], though less work has been reported on the use of social comparisons and its impacts on children's dietary intake and feeding.

\section{Beliefs about mealtimes}

Autonomy Promoting items reflected 1) teaching about foods (e.g. source, sensory properties and nutritional value) to create a positive atmosphere for children to learn about and try new foods and 2) role modeling to encourage children to eat fruits and vegetables [72]. This is an important construct given the previously documented relationship between beliefs and nutrition education and parenting communication efforts of ECE staff [80]. Coercive Beliefs reflected items that queried the effectiveness of pressuring children to try new foods (e.g., withholding seconds of other foods, the 'one bite' rule). Despite the detrimental impact of behaviors such as instrumental use of foods on child preference [13], mean scores for these items were near 3 (out of 5), reflecting variability or indecision regarding how to approach the introduction of novel foods to young children.

Concern-Based Control Beliefs, the final factor to emerge, reflected beliefs that adults know better than children how much, what and when food should be consumed. These items displayed the greatest mean scores of all the Belief items, suggesting that like parents, ECE educators desire to see children eat and feel that controlling mealtimes to that end is part of their responsibility [81]. When children do not eat the desired amount or types of foods, educators may feel it is in the best interest of the child for the adult to intervene.

\section{Endorsement of strategies}

ECE staff endorsed items consistent with Best Practice Guidance at varying rates, whereas items inconsistent with Best Practice Guidance most often received majority endorsement (i.e., staff endorsed practices that are not considered Best Practice). Consideration of the level of endorsement of all items, regardless of their retention based on variability in the factor analyses, provides a useful reflection on the ECE feeding environment. For example, within Structural Mealtime Strategies, the majority of educators $(>75 \%)$ endorsed supportive practices such as offering new foods, trying new foods, and letting children decide how much to eat. On the other hand, the majority also endorsed Unsupportive Practices, such as sending children away from the table when they do not want to stop eating and controlling the order in which children consumed foods. The challenges of helping children learn to recognize internal cues of satiety (to terminate eating), even when palatable food is still available, has not been studied, despite reports that ECE staff struggle with this situation, particularly when children come from food insecure households [82-84].

Similarly, within Verbal Mealtime Strategies, $>75 \%$ endorsed supportive practices such as talking about all foods and teaching about new foods but also sanctioned several items focused on Unsupportive Practices such as getting children to eat more (e.g., comment to the child eating well, ask them to eat something on their plate, ask children to take a bite). Conversely, some items regarded as Best Practice Guidance were endorsed by as few as $31 \%$ of educators (e.g., staff and children pass the food). In terms of Beliefs, mean scores consistent for Unsupportive Practices (e.g., adults know better than a child how much to eat) were higher than those aligned with supportive practice (e.g., children will try if they see me eat it). Overall, these findings suggest that there may be more room for training and intervention to increase adoption of best practices and to de-implement (i.e., remove, replace, reduce) $[85,86]$ practices and change beliefs that are not supportive of children's development.

\section{Limitations and strengths}

Our systematic approach to the development of this instrument has both limitations and strengths. A limitation to the potential generalizability of this work is the focus 
on data collection in Western states in the US in center-based care. Our results may not reflect the practices and beliefs of educators in other parts of the US or home-based providers. Another limitation is that three of the factors exhibited lower levels of internal consistency $(>0.50$ and $<0.60)$ as indicated by Kuder-Richardson values [44]. The goal of this study was to develop a tool with the least number of items that measure distinct constructs, with as little redundancy as possible. Though brevity is known to lead to lower internal consistency values compared to instruments with more items and greater redundancy $[62,63]$, given the objective of this study, pragmatic and reliability concerns were balanced. Finally, the wording of some items should be considered in relation to endorsement and conception of Best Practice Guidance. For example, strong, unambiguous wording is used in survey item development to avoid acquiescence bias and increase variability on the latent construct [44]. In this study where a binary response option was coded for Structural and Mealtime Strategies items, extreme wording was related to very low endorsement $(<15 \%)$ for items using words like "very" and "never." Moreover, the inconsistency in terms of degree of endorsement between agreement with practice and belief in practice suggest either a true disconnect between practice and belief, fear of reprisals, or social bias in reporting. Further development of the tool could assess the psychometric properties of the Feeding Strategies scales using consistent and full Likert scales and estimate intraclass correlation coefficients between centers in the same center and agency. Exploration of feeding practices at snack in child care settings is also warranted.

A primary strength of the AFC Strategies and Beliefs Survey was its employment of qualitative methods (expert input, survey design consultation, and cognitive testing interviews) with diverse populations and incorporation of feedback at each level of the survey design. This process was utilized to ensure that response sets were complete and that providers interpreted the questions and responses in a similar manner. Further, $78 \%$ of educators in our sample had at least some college education, and $23 \%$ had achieved either an undergraduate or graduate level degree. This level of education is slightly lower than national estimates that report 53\% of ECE settings-based and $30 \%$ of home-based providers have a college degree [87]. Finally, the inclusion of items within each construct of the AFC Strategies and Beliefs Survey that reflect both Best Practices and those strategies which fall short of these practices provides the ability to capture the range of classroom practices and beliefs related to feeding in ECE.

\section{Conclusions}

The AFC Strategies and Beliefs Survey is a promising self-report instrument with a strong factor structure consistent with the extant literature to measure practices and beliefs related to feeding and mealtimes specifically in the ECE setting. Feeding young children in group settings differs in many ways from feeding in a family setting; hence it is important that measures such as the AFC Strategies and Beliefs Survey capture the unique aspects of the ECE feeding environment. Further, this research adds to the growing body of areas of strength and opportunity, particularly those investigating cutting edge strategies for de-implementation of detrimental (i.e., unsupportive) beliefs and practices. Additional development work with the AFC Strategies and Beliefs instrument should explore test-retest reliability, convergent validity with other measures in the field, and predictive validity of this tool against classroom observations and child outcomes. Future studies also could look at group differences on these constructs among educators with varying characteristics (e.g., education, training, experience, ethnicity/culture, age of children served, population served, demands of food insecurity, provider personal characteristics like weight status and eating history). Finally, the sensitivity of this instrument in response to intervention should be explored. ECE educators are responsible for employing Best Practice Guidance in every aspect related to child development, including the feeding environment.

\section{Abbreviations \\ AFC: about feeding children; BMI: Body mass index; CA: California; CACFP: Child and adult care food program; CO: Colorado; ECE: early care and education; EFA: exploratory factor analysis; FIML: Full Information Maximum Likelihood; ID: Idaho; KR: Kuder-Richardson; NV: Nevada; SD: Standard deviation; US: United States; WLSMV: weighted least squares estimation}

\section{Acknowledgements}

The authors wish to acknowledge the efforts of the research team for their instrumental work and support throughout the study: Elizabeth Christiansen, Keri Nikolajewski, Elizabeth Price, Kirk Steinhorst, Ramona Beasley and Priscilla Salant. We also wish to thank the members of our expert panel and especially the child care providers who participated in the research. We also acknowledge Geeerish Sadasivan for his assistance with formatting the manuscript.

\section{Funding}

This research was supported by the National Initiative for Future Agriculture and Food Systems Grant no. 2001-52102-11202 from the USDA Cooperative State Research, Education and Extension Service. The project was also supported, in part, by the UAMS Translational Research Institute (TRI), grants UL1TR000039 and KL2TR000063 (TS) through the NIH National Center for Research Resources and the National Center for Advancing Translational Sciences, the Arkansas Biosciences Institute, NIH P20GM109096 (TS), and NIH K01 DK110141 (TS).

\section{Availability of data and materials}

The datasets used and/or analyzed during the current study will be available from the corresponding author on reasonable request.

\section{Authors' contribution}

TS conceived and executed the data analysis plan for this study and made substantial contribution to drafting and revising; MSG conceived of the overarching study, contributed to the design of the instrument, and made substantial contributions to interpretation of the data as well as the drafting and revising. LB and JF made substantial contributions to the development of the original instrument and contributed to the revising of this manuscript. SJ made substantial contributions to the design of the instrument as well as design and interpretation of the data analysis plan and the drafting and 
revising of this manuscript. All authors provided final approval and agree to be accountable for all aspects of this work.

\section{Ethics approval and consent to participate}

This protocol was approved by the University of Nevada, Reno Institutional Review Board. Institutional Review Board (IRB SA01/02-063). We conducted this study in accordance with all applicable government regulations and University of Nevada, Reno research policies and procedures. By returning surveys, all respondents provided consent.

\section{Consent for publication}

Not applicable.

\section{Competing interests}

The authors declare that they have no competing interests.

\section{Publisher's Note}

Springer Nature remains neutral with regard to jurisdictional claims in published maps and institutional affiliations.

\section{Author details}

'Department of Family and Preventive Medicine, University of Arkansas for Medical Sciences, 521 Jack Stephens Drive, Little Rock, AR 72205, USA. 2University of Nevada Cooperative Extension, 2558 So Elizabeth Street, Salt Lake City, UT 85406, USA. ${ }^{3}$ Food and Nutrition, University of Idaho, Moscow, ID 83844-3183, USA. ${ }^{4}$ Child, Family and Consumer Studies, Center on Disabilities and Human Development, University of Idaho, 1187 Alturas Drive, Moscow, ID 83844-1187, USA. ${ }^{5}$ Department of Pediatrics, Anschutz Medical Campus, Section of Nutrition, F-561, University of Colorado-Denver, 12,631 E 17th Ave, Rm \#2609, Aurora, CO 80045, USA.

\section{Received: 6 December 2017 Accepted: 27 August 2018}

\section{Published online: 10 September 2018}

\section{References}

1. National Household Education Surveys Program. National Center for Educational Statistics. 2012. https://nces.ed.gov/nhes/tables/nonrelative_ care.asp.

2. American Dietetic Association. Position of the American Dietetic Association: benchmarks for nutrition programs in child care settings. J Am Diet Assoc. 2005:105:979

3. Geoffroy MC, Power C, Touchette E, Dubois L, Boivin M, Séguin JR, et al. Childcare and overweight or obesity over 10 years of follow-up. J Pediatr. 2013;162:753-758.e1.

4. American Academy of Pediatrics., National Resource Center for Health and Safety in Child Care (U.S.), American Public Health Association., United States. Maternal and Child Health Bureau. Caring for our children : National health and safety performance standards : guidelines for out-of-home child care. American Academy of Pediatrics; 2002.

5. Merriam Webster. Best Practice | Definition of Best Practice

6. Larson N, Ward DS, Neelon SB, Story M. What role can child-care settings play in obesity prevention? A review of the evidence and call for research efforts. J Am Diet Assoc. 2011;111:1343-62. https://doi.org/10.1016/j.jada. 2011.06.007

7. Galloway AT, Fiorito LM, Francis LA, Birch LL. "Finish your soup": counterproductive effects of pressuring children to eat on intake and affect. Appetite. 2006;46:318-23. https://doi.org/10.1016/j.appet.2006.01.019.

8. Patton S, Dolan L, Powers S. Parent report of mealtime behaviors in young children with type 1 diabetes mellitus: implications for better assessment of dietary adherence problems in the clinic. J Dev Behav Pediatr. 2006;27:202-8.

9. Johnson SL, Birch LL. Parents' and children's adiposity and eating style. Pediatrics. 1994;94:653-61.

10. Keller K, Pietrobelli A, Johnson S, Faith M. Maternal restriction of children's eating and encouragements to eat as the "non-shared environment": a pilot study using the child feeding questionnaire. Int J Obes. 2006;30:1670-5.

11. Birch LL, Fisher JO, Davison KK. Learning to overeat: maternal use of restrictive feeding practices promotes girls' eating in the absence of hunger. Am J Clin Nutr. 2003:78:215-20.

12. Fisher J, Birch $L$. Restricting access to palatable foods affects children's behavioral response, food selection, and intake. Am J Clin Nutr. 1999;69: 1264-72.
13. Birch L, Birch D, Marlin D, Kramer L. Effects of instrumental consumption on children's food preference. Appetite. 1982;3:125-34.

14. Birch L, Marlin D, Rotter J. Eating as the "means" activity in a contingency: effects on young children's food preference. Child Dev. 1984;55:431-9.

15. Hughes S, Power T, Fisher J, Mueller S, Nicklas T. Revisiting a neglected construct: parenting styles in a child-feeding context. Appetite. 2005;44:83-92.

16. Fisher J, Mitchell D, Smiciklas-Wright H, Birch L. Parental influences on young girls' fruit and vegetable, micronutrient, and fat intakes. J Am Diet Assoc. 2002;102:58-64.

17. Birch L, Fisher J, Grimm-Thomas K, Markey CN, Sawyer R, Johnson SL. Confirmatory factor analysis of the child feeding questionnaire: a measure of parental attitudes, beliefs and practices about child feeding and obesity proneness. Appetite. 2001;36:201-10.

18. Sherman J, Alexander M, Clark L, Dean A, Welter L. Instruments measuring maternal factors in obese preschool children. West J Nurs Res. 1992;14:555-75.

19. Patrick H, Nicklas T. A review of family and social determinants of children's eating patterns and diet quality. J Am Coll Nutr. 2005:24:83-92.

20. Dev DA, McBride BA. Academy of nutrition and dietetics benchmarks for nutrition in child care 2011: are child-care providers across contexts meeting recommendations? J Acad Nutr Diet. 2013;113:1346-53.

21. Dev DA, Speirs KE, McBride BA, Donovan SM, Chapman-Novakofski K. Head start and child care providers' motivators, barriers and facilitators to practicing family-style meal service. Early Child Res Q. 2014;29:649-59.

22. Elford L, Brown A. Exploring child-feeding style in childcare settings: how might nursery practitioners affect child eating style and weight? Eat Behav. 2014;15:314-7.

23. Musher-Eizenman D, Holub S. Comprehensive feeding practices questionnaire: validation of a new measure of parental feeding practices. Pediatr Psychol. 2007;32:960-72.

24. Freedman MR, Alvarez KP. Early childhood feeding: assessing knowledge, attitude, and practices of multi-ethnic child-care providers. J Am Diet Assoc 2010;110:447-51.

25. Vaughn AE, Ward DS, Fisher JO, Faith MS, Hughes SO, Kremers SPJ, et al. Fundamental constructs in food parenting practices: a content map to guide future research. Nutr Rev. 2016;74:98-117.

26. Schmitt N, Kuljanin G. Measurement invariance: review of practice and implications. Hum Resour Manag Rev. 2008;18:210-22.

27. Gubbels JS, Sleddens EF, Raaijmakers LC, Gies JM, Kremers SP. The child-care food and activity practices questionnaire (CFAPQ): development and first validation steps. Public Health Nutr. 2016;19:1964-75.

28. Ward DS, Mazzucca S, McWilliams C, Hales D. Use of the environment and policy evaluation and observation as a self-report instrument (EPAO-SR) to measure nutrition and physical activity environments in child care settings: validity and reliability evidence. Int J Behav Nutr Phys Act. 2015;12:124

29. Fallon M, Halloran K, Gorman K, Ward D, Greene G, Tovar A. Self-reported and observed feeding practices of Rhode Island head start teachers: knowing what not to do. Appetite. 2018;120:310-7. https://doi.org/10.1016/ J.APPET.2017.09.009.

30. Anundson K, Sisson SB, Anderson M, Horm D, Soto J, Hoffman L. Staff foodrelated behaviors and Children's tastes of food groups during lunch at child Care in Oklahoma. J Acad Nutr Diet. 2018;118:1399-407.

31. Song WO, Song S, Nieves V, Gonzalez A, Crockett ET, Larson A, et al. Nutritional health attitudes and behaviors and their associations with the risk of overweight/obesity among child care providers in Michigan migrant and seasonal head start centers. BMC Public Health. 2016;16:648.

32. Sharma S, Dortch KS, Byrd-Williams C, Truxillio JB, Rahman GA, Bonsu P, et al. Nutrition-related knowledge, attitudes, and dietary behaviors among head start teachers in Texas: a cross-sectional study. J Acad Nutr Diet. 2013; 113:558-62.

33. Swindle TM, Ward WL, Bokony P, Whiteside-Mansell L. A cross-sectional study of early childhood educators' childhood and current food insecurity and dietary intake. J Hunger Environ Nutr. 2018;13(1):40-54.

34. Henderson K, Grode G, Middleton A, Kenney E, Falbe J, Schwartz M. Validity of a measure to assess the child-care nutrition and physical activity environment. J Am Diet Assoc. 2011:111:1306-13.

35. Benjamin SE, Ammerman A, Sommers J, Dodds J, Neelon B, Ward DS. Nutrition and physical activity self-assessment for child care (NAP SACC) results from a pilot intervention. J Nutr Educ Behav. 2007;39:142-9. 
36. Seward K, Wolfenden L, Wiggers J, Finch M, Wyse R, Oldmeadow C, et al. Measuring implementation behaviour of menu guidelines in the childcare setting: confirmatory factor analysis of a theoretical domains framework questionnaire (TDFQ). Int J Behav Nutr Phys Act. 2017;14:45.

37. Copeland KA, Sherman SN, Khoury JC, Foster KE, Saelens BE, Kalkwarf HJ. Wide variability in physical activity environments and weather-related outdoor play policies in child care centers within a single county of Ohio. Arch Pediatr Adolesc Med. 2011;165:435-42.

38. Falbe J, Kenney EL, Henderson KE, Schwartz MB. The wellness child care assessment tool: a measure to assess the quality of written nutrition and physical activity policies. J Am Diet Assoc. 2011;111:1852-60.

39. Sigman-Grant M, Christiansen E, Branen L, Fletcher J, Johnson SL. About feeding children: mealtimes in child-care centers in four western states. J Am Diet Assoc. 2008;108:340-6.

40. Swindle TM, Patterson Z, Boden CJ. A qualitative application of the Belsky model to explore early care and education teachers' mealtime history, beliefs, and interactions. J Nutr Educ Behav. 2017:49

41. Rice ME, Grusec JE. Saying and doing: effects on observer performance. J Pers Soc Psychol. 1975;32:584-93.

42. Staub E. Effects of persuasion and modeling on delay of gratification. Dev Psychol. 1972;6:166-77.

43. Grusec JE, Saas-Kortsaak P, Simutis ZM. The role of example and moral exhortation in the training of altruism. Child Dev. 1978;49:920

44. DeVellis RF. Scale development: theory and applications. Third edit. Thousand Oaks, CA: SAGE Publications; 2012.

45. Davis AM, Canter KS, Stough CO, Gillette MD, Patton S. Measurement of mealtime behaviors in rural overweight children: an exploratory factor analysis of the behavioral pediatrics feeding assessment scale. J Pediatr Psychol. 2014;39:332-9.

46. Hendy HM, Williams KE, Camise TS, Eckman N, Hedemann A. The parent mealtime action scale (PMAS). Development and association with children's diet and weight. Appetite. 2009;52:328-39.

47. Muthen BO, Muthen LK. Mplus Version 7. 2007.

48. Muthen B, du Toit SH., Spisic D. Robust inference using weighted least squares and quadratic estimating equations in latent variable modeling with categorical and continuous outcomes. Psychometrika. 1997.

49. Gaskin C, Happell B. On exploratory factor analysis: a review of recent evidence, an assessment of current practice, and recommendations for future use. Int J Nurs Stud. 2014;51:511-21.

50. Horn J. A rationale and test for the number of factors in factor analysis. Psychometrika. 1965;30:179-85.

51. Allison PD. Handling missing data by maximum likelihood. Cary, NC: SAS Institute; 2012.

52. Tavakol M, Dennick R. Making sense of Cronbach's alpha. Int J Med Educ. 2011;2:53-5.

53. Streiner DL. Starting at the beginning: an introduction to coefficient alpha and internal consistency. J Pers Assess. 2003;80:99-103.

54. Benjamin Neelon SE, Briley ME. Position of the American dietetic association: benchmarks for nutrition in child care. J Am Diet Assoc. 2011 . 111:607-15.

55. Ammerman A, Ward D, Benjamin S, Ball S. An intervention to promote healthy weight: nutrition and physical activity self-assessment for child care (NAP SACC) theory and design. Prev Chronic Dis. 2007:4:A67.

56. Fletcher J, Branen L, Price B, Matthews S. Building mealtime environments and relationships. An inventory of mealtime practices for feeding young children in group settings. University of Idaho; 2005; 2010.

57. Ward D, Hales D, Haverly K, Marks J, Benjamin S, Ball S, et al. An instrument to assess the obesogenic environment of child care centers. Am J Health Behav. 2008:32

58. Lanigan JD. The relationship between practices and child care providers' beliefs related to child feeding and obesity prevention. J Nutr Educ Behav. 2012:44:521-9.

59. Hughes SO, Cross MB, Hennessy E, Tovar A, Economos CD, Power TG. Caregiver's feeding styles questionnaire. Establishing cutoff points. Appetite. 2012;58:393-5

60. Buck JH. The two bite Club ebook. J Nutr Educ Behav. 2016;48:434.

61. Satter E. Eating competence: definition and evidence for the Satter eating competence model. J Nutr Educ Behav. 2007;39(5 Suppl):S142-53.

62. Wardle J, Cooke LJ, Gibson EL, Sapochnik M, Sheiham A, Lawson M. Increasing children's acceptance of vegetables; a randomized trial of parentled exposure. Appetite. 2003;40:155-62.
63. Cooke LJ, Chambers LC, Añez EV, Croker HA, Boniface D, Yeomans MR, et al. Eating for pleasure or profit. Psychol Sci. 2011;22:190-6.

64. Newman J, Taylor A. Effect of a means-end contingency on young children's food preferences. J Exp Child Psychol. 1992;53:200-16.

65. Sanders MR, Patel RK, le Grice B, Shepherd RW. Children with persistent feeding difficulties: an observational analysis of the feeding interactions of problem and non-problem eaters. Health Psychol. 1993;12:64-73.

66. Wardle J, Herrera M-L, Cooke L, Gibson EL. Modifying children's food preferences: the effects of exposure and reward on acceptance of an unfamiliar vegetable. Eur J Clin Nutr. 2003;57:341-8.

67. Office of Head Start. 1302.31 Teaching and the learning environment. | ECLKC. Legislation and regulations: Head Start Program Performance Standards (45 CFR part 1304.23 Child Nutrition). US Department of Health and Human Services, Administration for Children and Families. https://eclkc. ohs.acf.hhs.gov/policy/45-cfr-chap-xiii/1302-31-teaching-learningenvironment. Accessed 18 Dec 2016.

68. Ogata BN, Hayes D. Position of the academy of nutrition and dietetics: nutrition guidance for healthy children ages 2 to 11 years; 2014. https://doi. org/10.1016/j.jand.2014.06.001.

69. Kharofa RY, Kalkwarf HJ, Khoury JC, Copeland KA. Are mealtime best practice guidelines for child care centers associated with energy, vegetable, and fruit intake? Child Obes. 2016;12:1-7.

70. Blaine RE, Davison KK, Hesketh K, Taveras EM, Gillman MW, Benjamin Neelon SE. Child care provider adherence to infant and toddler feeding recommendations: findings from the baby nutrition and physical activity selfassessment for child care (baby NAP SACC) study. Child Obes. 2015;11:304-13.

71. Vandeweghe L, Moens E, Braet C, Van Lippevelde W, Vervoort L, Verbeken S. Perceived effective and feasible strategies to promote healthy eating in young children: focus groups with parents, family child care providers and daycare assistants. BMC Public Health. 2016;16

72. Blissett J. Relationships between parenting style, feeding style and feeding practices and fruit and vegetable consumption in early childhood. Appetite. 2011;57:826-31.

73. Mitchell GL, Farrow C, Haycraft E, Meyer C. Parental influences on children's eating behaviour and characteristics of successful parent-focussed interventions. Appetite. 2013;60

74. Orrell-Valente JK, Hill LG, Brechwald WA, Dodge KA, Pettit GS, Bates JE. "Just three more bites": an observational analysis of parents' socialization of children's eating at mealtime. Appetite. 2007;48:37-45.

75. Birch LL, McPheee L, Shoba B, Steinberg L, Krehbiel R. "Clean up your plate": effects of child feeding practices on the conditioning of meal size. Learn Motiv. 1987:18:301-17.

76. Hendy HM. Comparison of five teacher actions to encourage children's new food acceptance. Ann Behav Med. 1999;21:20-6.

77. Ramsay SA, Branen LJ, Fletcher J, Price E, Johnson SL, Sigman-Grant M. "Are you done?" Child care providers' verbal communication at mealtimes that reinforce or hinder children's internal cues of hunger and satiation. J Nutr Educ Behav. 2010;42:265-70.

78. Hughes S, Anderson C, Power T, Micheli N, Jaramillo S, Nicklas T. Measuring feeding in low-income African-American and Hispanic parents. Appetite. 2006;46:215-23.

79. Hanus MD, Fox J. Assessing the effects of gamification in the classroom: a longitudinal study on intrinsic motivation, social comparison, satisfaction, effort, and academic performance. Comput Educ. 2015;80:152-61.

80. Lanigan J. The relationship between practices and child care providers' beliefs related to child feeding and obesity prevention. J Nutr Educ Behav. 2012;44:521-9.

81. Costanzo PR, Woody EZ. Domain-specific parenting styles and their impact on the Child's development of particular deviance: the example of obesity proneness. J Soc Clin Psychol. 1985;3:425-45.

82. Sigman-Grant M, Rd P, Christiansen E, Fernandez G, Edd JF, Johnson SL, et al. Hungry Mondays: low-income children in childcare. J Hunger Environ Nutr J. 2008:24:1932-248.

83. Lumeng JC, Kaplan-Sanoff M, Shuman S, Kannan S. Head start teachers' perceptions of children's eating behavior and weight status in the context of food scarcity. J Nutr Educ Behav. 2008;40:237-43.

84. Gooze RA, Hughes CC, Finkelstein DM, Whitaker RC. Obesity and food insecurity at the same table: how head start programs respond. Prev Chronic Dis. 2012;9:E132.

85. Prasad V, loannidis JP. Evidence-based de-implementation for contradicted, unproven, and aspiring healthcare practices. Implement Sci. 2014;9:1. https://doi.org/10.1186/1748-5908-9-1. 
86. Bodegom-Vos L, Davidoff F, Marang-van de Mheen PJ. Implementation and de-implementation: two sides of the same coin? BMJ Qual Saf. 2016.

87. National Survey of Early Care and Education Project Team. Number and Characteristics of Early Care and Education (ECE) Teachers and Caregivers: Initial Findings from the National Survey of Early Care and Education (NSECE). Washington, DC; 2013. https://www.acf.hhs.gov/sites/default/files/ opre/nsece_wf_brief_102913_0.pdf. Accessed 20 Mar 2017.

Ready to submit your research? Choose BMC and benefit from:

- fast, convenient online submission

- thorough peer review by experienced researchers in your field

- rapid publication on acceptance

- support for research data, including large and complex data types

- gold Open Access which fosters wider collaboration and increased citations

- maximum visibility for your research: over $100 \mathrm{M}$ website views per year

At BMC, research is always in progress.

Learn more biomedcentral.com/submissions 